\title{
Revenue Management: Automation, Challenges, \& Legal Perspectives of County Governments in Kenya
}

\author{
Dr. Nebert Ombajo Mandala, PhD, CPAK, CPSK, CISA \\ Victor Odhiambo, LLM, LLB) \\ Carlton Hussein Wanga, BSc, MSc \\ Tritek Consulting Limited, Kenya
}

Doi:10.19044/esj.2020.v16n25p196 URL:http://dx.doi.org/10.19044/esj.2020.v16n25p196

\begin{abstract}
In today's competitive and fast-paced business landscape, getting the most out of every available resource is not an option but rather a requirement. Organizations are taking a highly proactive approach to systems modernization and operations in an effort to increase efficiency and effectiveness in their operations. There is an increasing need by governments to enhance revenue collection through taxes to meet the ever-increasing financial expenditures budgeted by countries. It has been noted that most of the county governments were not meeting their own targets for own-source revenue and over time this has been reducing. This paper aims to establish the status of automation of revenue collection by county governments in Kenya, document the legal framework, establish the challenges of revenue collection and management, and also sought to determine whether there exists an optimal revenue automation model that can be adopted for the purpose of optimizing performance. The design of this research was done using a descriptive survey. The population for this study was composed of 47 county governments. Stratified proportionate random sampling technique was used to select the sample of 24 counties spread across the entire country. The study used a semistructured self-administered questionnaire to collect data from the respondents. The study established that the counties face a myriad of challenges including weak revenue bases, lack internal audits, have poorly trained personnel, use partially automated revenue collection systems, poor infrastructure, and some county revenue officers are reluctant to embrace change. This, however, has a negative impact on revenue collection within the counties. The results further show that adherence by counties to the provided guidelines, training, and technical assistance was widely varied and disparate. This ranged from counties that did very little to nothing in enabling and enhancing their OSR, to those that partially and/or conveniently followed guidelines where it suited them, to those that made honest efforts to comply.
\end{abstract}


A model of a good automated system is also presented. The study recommends that counties should fully automate their revenue management to enhance efficiency and service delivery to their citizens.

Keywords: Automation, Revenue management, County governments, Tax, Data

\subsection{Introduction}

The modern business environment is characterized by uncertainty, risk and dynamism, making it harder to forecast and manage factors, which are more likely to impact institutional performance (Sanda, Mikailu \& Garba, 2005). This research paper proposes that adoption of automation in revenue management is among the most viable options of improving institutional performance, and mitigating uncertainty and risk in a modern corporate environment. Moreover, it increases the possibility of getting additional investment capital due to reduced risk levels.

The Constitution of Kenya 2010 introduces a decentralized and twotier system of governance, national and county governments. Political, administrative, and financial authority has been transferred from the national level to independent sub-national level units known as counties. Furthermore, the fourth schedule of the constitution mandates county governments to provide a range of services as set out by law to its constituents and has a legal authority to do so. It also has legal powers to enforce its executive and regulatory decisions on its citizens without resorting to unnecessary social pressures to achieve this. Its instruments define its area of authority and basis for representation on its political leadership platform. The counties are allowed to legislate on matters falling within their province and are allowed to collect taxes that are specified under the constitution. To this end, they have their own staff and revenue referred to as own-source revenue (Kamolo, 2014). County operations are funded from both the national consolidated fund and collection of revenue from their own local sources. Revenue collection mainly comprises of parking fees, business permits, land rates, and other service fees such as local health facility payments. The constitution bars the counties from collecting formal taxes, which are collected by the national government through a collection agency known as the Kenya Revenue Authority.

Devolution of revenue collection and management to the counties and subsequently to other administrative units within the county comes with enormous challenges, especially lack of network and communication infrastructure needed to facilitate revenue collection. There is, therefore, a need to employ alternative technologies (Khaunya, Wawire \& Chepng'eno, 2015). 
Revenue management in the public sector is an integral component of fiscal policy and administration in any economy because of its influence on government operations. It is the fuel of every government as it is the main instrument through which government funding is ensured. Tax revenue collection should comply with best practices of equity, ability to pay, economic efficiency, convenience, and certainty (Visser \& Erasmus, 2005). For any country to match in performance with the growth and expectations of its citizens, it needs to increase its fiscal depth without incurring costly recurring overheads (Gidisu, 2012).

Revenue collection enhancement is vital in promoting efficiency in the service delivery and economic development of county governments. However, most county governments face serious challenges in their revenue management (Balunywa, Nangoli, Mugerwa, Teko \& Mayoka, 2014), where governments are not able to collect sufficient funds to cover their budget expectations. Furthermore, for many years, revenue collection has been marred by fraud and other inefficiencies (Ngotho \& Kerongo, 2014).

There is an increasing need by the government to collect more revenue to accommodate the increasing expenditure as budgeted. Automated systems have been proven to be capable of introducing massive efficiencies to processes that can result in increased revenue collections (Zhou \& Madhikeni, 2013). Application of technological solutions towards the strategic goals for government is a key step towards transforming government into an entity that can keep abreast of the needs, requirements, and expectations of today's modern world (de-Wulf \& Sokol, 2005).

Revenue administration automation has a positive impact on the cost of tax administration, automation, and effectiveness of revenue collection. In addition, automation of process at revenue collection points has a positive impact on the tax clearance time (Haughton \& Desmeules, 2001). Automation of Tax-Information Processing System does not require high equipment cost, but it rather helps to ease the burden of over-staffing and high re-engineering cost confronted by government institutions among others. Automation systembased approaches have become an important vehicle for achieving efficiency in tax administration (UNCTAD, 2006). Hence, automation impacts on the efficiency of tax administration. Efficiency of tax administration is defined as costs, tax clearance time, and effectiveness of revenue collection.

Several counties are generating less revenue than what the defunct local authorities that lay within their boundaries raked in collectively (ICPAK, 2014). Thus, this is raising concerns on the capacity of the devolved units in raising their own revenue. The report further noted that the counties have weak revenue bases, lack internal audits, have poorly trained personnel, use manual revenue collection systems, and some county revenue officers are reluctant to embrace change. However, this has impacted negatively on revenue collection 
within the counties. In a move to create a transparent database so as to track payments in real-time, improve efficiency, reduce cash transactions as well as ensure there are no leakages in the revenue systems, the county governments have tried to step up revenue collection by phasing out the manual collection system to pave way for fully automated ones. All this is geared towards improving its revenue base (Amin, 2013).

Non-automated systems of revenue are associated with problems of tracking and identifying fraud or rogue revenue collectors. This is due to usage of manual or centralized systems due to the resources and overheads needed to monitor and control the above problems. Manual collection of payments at several service points lead to delayed customer service with built-in risk of manual cash management and minimal payment channels. Disparate payment applications and lack of integration to the back-office applications brought about delayed and possibly erroneous analysis and reporting (Prichard, 2010).

Indeed, these basic fundamentals play a role in determining the efficiency of the government operations, hence, aspirations towards increase in revenue collections. Automation of process at revenue collection points has a positive impact on the tax clearance time (Haughton \& Desmeules, 2001). Conversely, the automation of tax system, rather than just affecting the revenue collection, expenditure and clearance time as highlighted above, will also impact the overall staffing, confirming that the right measure of tax assessment has been undertaken so as to deter underpayments and tax evasions, and proper ways of accountability and audit trails instigated so as to curb embezzlements. This is usually attained successfully by synchronizations of various systems towards a common repository mapping which is a fundamental tool in automation (Dramod, 2004).

Several studies have been done previously on strategy for revenue generation. Latema (2011) in a study on the business models for revenue generation and enhancement adopted by county governments in Kenya recommends the need for county governments in Kenya to innovate new models of revenue enhancement and revenue generation. Victor (2014) highlighted various ways of engendering public participation in county government governance by giving a general overview of strategies of raising revenues at the county levels. Kariuki (2009) did a survey of revenue enhancement strategies by local authorities. It was observed that to enhance revenue collection by local authorities, political will, technological reforms, taxpayer education, and incentives to those involved are required so as to enhance the revenue mobilization effort.

\subsection{Research Objectives}

The objective of this research is to establish the status of automation of revenue collection by county governments in Kenya, establish the 
challenges of revenue collection and management, and also sought to determine whether there exists an optimal revenue automation model that can be adopted for the purpose of optimizing performance.

Specifically, the study is focused on four key areas:

a) Assessing legal and regulatory compliance to existing County Financing Legislation ${ }^{7}$ and Commission of Revenue Allocation (CRA) revenue guidelines;

b) Assessing the level and extent of business process automation and efficacy of the technology systems in use in revenue management;

c) Assessing the effectiveness of revenue collection enforcement, revenue administration and management;

d) Determining an optimal revenue collection model for county governments;

e) Assessing the challenges bedeviling county governments in revenue management.

\subsection{Research Problem}

Right from inception, county governments have made efforts to automate their revenues with the main objective being the enhancement of Own-Source Revenue (OSR). There are a total of 33 counties that have automated their revenues so far; however, the automation has been characterized by enormous challenges which include: the high cost of automation, budget constraints, lack of goodwill from some county leadership, vested interest among others. Additionally, a number of the counties have experienced system failures leading to inability to collect revenue. On 7 th February 2019, the President of the Republic of Kenya issued a directive on the formation of a multi-agency task force to deliver a single Integrated County Revenue Management System (ICRMS) to be used across all 47 county governments.

The directive was consistent with the recommendations that had been made in three consecutive annual County Revenue Automation Conferences (CRAC) which the Commission on Revenue Allocation (CRA) has been hosting in conjunction with other stakeholders. The main recommendations from CRACs were: Having an integrated revenue management system that can be shared by all county governments, Shared county revenue infrastructure for reduction of the total cost of ownership, Ensure standardization in the revenue management system, Develop an intergovernmental systems integration platform to enable sharing of data between the national and county governments and among county governments for

${ }^{7}$ Public Finance Management Act 2012 
better decision making, and having a unified system database for the enhanced disaster recovery plan.

In addition, the CRA in conjunction with the United States Agency for International development (USAID) through the Agile and Harmonized Assistance for Devolved Institutions (AHADI) Program in 2017 carried out an assessment study on county revenue automation systems. Here, they reviewed a sample of 15 county revenue systems with an intention of assessing automation impact and gaps. This recommendation on the assessment of 15 county revenue systems was validated and endorsed by county governments in the 3rd County Revenue Enhancement and Automation Conference (CREAC) in April 2018. Weaknesses in the assessed revenue management systems included: partial automation of revenue streams, multiple independent revenue management systems, weak internal control, inconsistent cash and bank reconciliations, inadequate staffing and technical capacity of staff, and ownership of data by the vendors. Other weaknesses highlighted by the Policy to Support Enhancement of County Governments Own-Source Revenue include inadequate policies and legislation, low automation and integration of revenue administration, human resource capacity deficits, weaknesses in enforcement, the multiplicity of fees and charges, and ineffective controls and audit mechanisms.

County governments are assigned fourteen functions which demand adequate resources to implement. The resources at the disposal of the counties include shareable revenue, conditional allocation, and own-source revenue. The study concluded that the weak performance in OSR has weakened the ability of counties to perform their functions, leading to accumulation of pending bills by some county governments.

The National Policy Supporting Enhancement of County Government's Own-Source Revenue seeks to remedy the weaknesses identified through proposed policy, legislative and institutional reforms. The proposed reforms in the policy aim at strengthening the legal underpinnings for revenue collection and its link with policy objectives; achieving efficiency in revenue administration; enhancing governance and promoting transparency; and making public participation more effective. A range of national-level legislative reforms has been proposed to support the implementation of the policy encompassing land, entertainment, trade, tourism, agriculture, and the financing of urban areas and cities.

It is incontestable that the development of an integrated revenue management system would provide the necessary platform to support county governments to more efficiently collect and manage own-source revenue and to assist the decision-making process through improved data collection, visual data representation, sophisticated reports, and analytical metrics. The 
foregoing encompassed the thrust of the guidelines and standards issued by the Commission to the county governments.

This research seeks to bridge this gap by documenting the challenges facing county governments on revenue automation and further advising on an optimal revenue automation model that has worked in counties that have improved their own-source revenue.

\subsection{County Governments Revenue Management in Kenya}

The Commission on Revenue Allocation (CRA) (otherwise known as the Commission) is established under Article 215 of the 2010 Constitution with its functions further spelled out in Article 216 of the Constitution. The primary mandate of CRA is to provide an objective and independent framework for equitable sharing of nationally collected revenue between the national and county governments. CRA espouses the principles relating to public finance, the bill of rights, national values as well as the principles of good governance, to the extent that they apply to Public Financial Management (PFM). In this context, CRA continues to play a significant role in promoting and advancing accountability, development, service delivery, and equity through its activities and policy recommendations.

The Commission's mandate on PFM is provided for under Article 216(2) which states that, "The Commission shall also make recommendations on other matters concerning the financing of, and financial management by, county governments as required by the Constitution and national legislation" and Article 216(3)(c) which states that, "in making recommendations, the Commission shall seek to encourage fiscal responsibility." The responsibility of the Commission entails making recommendations that ensure fiscal responsibility at both level of government. Furthermore, CRA is required to ensure that financial management by county governments is carried out in accordance with provisions of the Constitution and national legislation.

In exercise of its mandate to make recommendations on the basis for revenue sharing, the Commission, inter alia, considers universal fiscal decentralization principles, the criteria for revenue sharing as set out in the Constitution under Article 203 and the assignment of devolved functions under the fourth schedule of the Constitution. Based on the Commission's recommendations, the national assembly in June 2016 passed the secondgeneration county government's revenue sharing formula as follows; 
Figure 1.

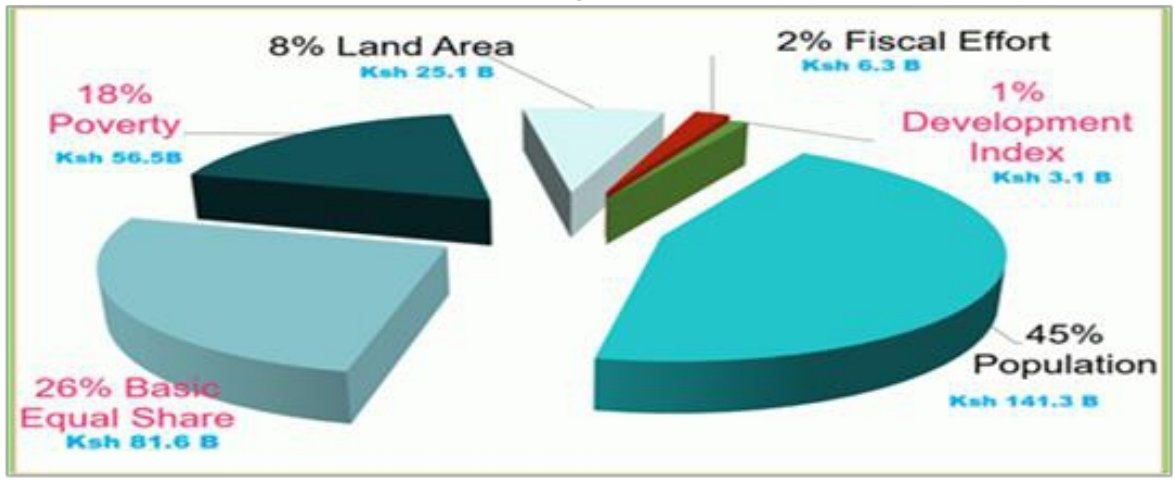

Source: Author, 2020

Fiscal discipline (effort) is one of the parameters that determine the share of equitable revenue that a county receives. The need for fiscal discipline has its origin both in the Constitution and the Law as documented below: Under Article 203(1)(e), the Constitution provides for fiscal capacity and efficiency as one of the determinants for revenue share; Under Article 216(3)(c), the Constitution mandates the CRA to factor in fiscal responsibility as part of the recommendations governing the sharing of revenue; and Section 107 of the Public Finance Management Act lays out the fiscal responsibility that counties have to conform to as pertains public finances and expenditure.

The Constitution as seen in Article 216(3)(c) mandates the Commission to encourage fiscal responsibility by county governments in the management of public finances. Fiscal discipline is appreciated as strict adherence to budgeted and spending targets, and maintenance of borrowing at levels that are financially sustainable and compatible with short-term and long-term macroeconomic capacity of a government, whether national or local, whilst considering all related risks. Thus, fiscal discipline pertains to all key measures of fiscal performance: the total revenue, the financial balance, and the public debt. Consequently, it has a desired outcome with respect to planning, allocation, and management of public resources.

In addition to promoting prudent public financial management, the Commission under Article 216(3)(b) is further mandated to define and enhance revenue sources of national and county governments. Direct raising of revenues from the local tax base, vis-à-vis principally relying on allocations from the exchequer, has the additional benefit of creating greater proximate obligation for the county governments to efficiently deliver on due services and fully account for revenues received from their citizenry.

To this end, the Commission at its outset, inter alia, developed and issued guidelines on the development of enabling county financing policies and legislation and on the implementation of Revenue Management Systems 
(RMS) towards instilling the following key attributes in the county revenue collection and management processes: Efficiency, Effectiveness, Accuracy, Transparency, Fraud, Taxpayer self-compliance, and Enforcement \& Compliance.

As counties during this first phase of devolution worked with varied efforts to attend to pertinent issues related to own-source revenue (OSR) collection and management, the Commission undertook the following roles and responsibilities: Recommended and advised on standards and guidelines to be used by counties to procure/develop the Revenue Collection Systems; advised on the policy, regulations and legislations governing OSR collection and management; and advised and shared best practices and experiences on revenue collection and automation.

The Commission additionally supported the county governments to develop revenue administration legislation through training, provision of technical assistance, and development of a handbook on model revenue raising model laws. The Commission also engaged counties to share lessons, challenges, and opportunities in revenue automation. A cardinal requirement of the guidelines issued by the CRA was that the Revenue Automation Systems adopted by the county governments should have had the capability to fully integrate with IFMIS to ensure accountability in revenue reporting and tracking.

The Constitution of Kenya allows counties to raise taxes and collect own revenue - property tax, entertainment tax, and user charges. Unfortunately, it is becoming more evident that the county governments are increasingly getting more reliant on fiscal transfers from the national government as opposed to devising ways and means of galvanizing additional sources of revenue from their own sources. County governments are yet to attain significant increases in their revenue collection bids. This is partly attributable to the fact that performance of local revenue is still undermined by low tax bases, external interferences from local politics, insufficient baseline information critical to revenue collection, administrative weaknesses, and poor utilization and management of collected revenues.

Under the 2010 Constitution, the financial resourcing of county government is done through the following means: Equitable share of at least 15 percent of most-recently audited revenue raised nationally (Article 202(1) and 203(2)); Additional conditional and unconditional grants from the National Government's share of revenue (Article 202(2)); Equalization Fund based on half of one percent of revenue raised nationally (Article 204); Local revenues in form of taxes, charges and fees; and Loans and grants. Based on the above, it is evident that counties have a constitutional basis for the levying of taxes, charges, and fees. It is therefore expected of counties to formulate a clear policy and legislative framework that aid their collection of these taxes, 
user fees, and levies. Even though taxes are an important source of revenue required for proper functioning and provision of services by both national and county governments, it is important to note that the taxes raised by the county governments must be formulated in a manner that is responsible and not prejudicial to national economic interests as provided for under article 209(5) of the Constitution.

\subsection{Theoretical Review}

\subsubsection{Optimal Tax Theory}

Optimal tax theory is based on the foundational work of Ramsey et al. (1928). The standard theory of optimal taxation posits that a tax system should be chosen to maximize a social welfare function subject to a set of constraints. The social planner is posited as a utilitarian: that is, the social welfare function is based on the utilities of individuals in the society. Optimal tax theory is concerned with the ideal level and form of economic redistribution. The optimal tax theory seeks to determine how government can maximize social welfare through taxes and transfers, without increasing the sacrifice on the part of tax payers (Prichard, 2010).

Whether conscious or not, optimal tax theory actually embodies a resource egalitarian view of distributive justice to a large extent (Holniker, 2005). However, the reasoning behind the theory's principles emphasizes incentives, efficiency, and the information that choices reveal about individual wellbeing. This theory indicates that optimal taxation is a function of tax charge and shows how this tax is collected to ensure fair redistribution of welfare. This theory was relevant to this study since revenue automation aims at increasing tax administration efficiency.

\subsubsection{Rational Expectations Theory of Technology Adoption}

Rational expectations theory of technology adoption was developed by Davis (1989). The theory posited that maximizing adoption of technology requires an understanding of the motivation of different groups of users and focusing on the deployment of messages and materials to address their perspectives. This theory indicates that much of the technology adoption decision depends on a firm's expectations about the benefits and costs of the technology. In this research, the rational expectations theory was used to test how the county staff had embraced the automation. This theory further postulates that adoption of automation depends on how the stakeholders value it in terms of bringing benefits to the operations and / or reducing costs and increasing efficiency. This theory was therefore valuable since it provided the researcher with a theoretical framework to test the automation effect (Gutierrez, 2008). 


\subsubsection{Technological Determinism}

Technological determinism (TD) is a reductionist theory and states that technology is a social structure or a force which drives change. TD changes the organisational culture, structure, reporting line, norm, and many other aspects including the modes of operations. The two main hypotheses that technological determinism depends on are; belief that the technical base of a society is the fundamental condition affecting all patterns of social existence, and belief that technological change is the single most important source of change in a society. Critics like Chandler (2000) states that other than technological issue, other factors have driving forces and some of them include political issues, class interests, economic pressures, educational background, general attitudes and others. TD has also had a long and controversial history in the social sciences in general and in organization studies in particular. Critics of TD argue variously that technology itself is socially determined, that technology and social structures coevolve in a nondeterministic, emergent process, or that the impact of any given technology depends mainly on how it is implemented which is in turn socially determined. Given the proliferation of new technologies in modern capitalism, the TD debate is continually renewed.

\subsection{Research Methodology \& Data Analysis}

The study was a descriptive correlational survey. By using data from county governments in Kenya, the research sought to determine the status of automation of revenue collection by county governments in Kenya, establish the challenges of revenue collection and management, and also sought to determine whether there exists an optimal revenue automation model that can be adopted for the purpose of optimizing performance. The design of this research was done using a descriptive survey. The population for this study was composed of 47 county governments. Stratified proportionate random sampling technique was used to select the sample of 24 counties spread across the entire country. The study used a semi-structured self-administered questionnaire to collect data from the respondents. Quantitative data was analysed by descriptive analysis using SPSS and presented in form of frequency tables. Content analysis was used for the qualitative data and then presented in prose.

The data collected was prepared, coded, analysed, organized, and used to report the findings as well as results of the hypotheses tests. In getting the data ready for analysis, data editing, standardization, coding, and categorization was undertaken. Descriptive statistics which included measures of central tendency were computed. Standard deviation was adopted to explore dispersion in the collected data. All the variables of the research were described, and the salient characteristics of the data collected were provided 
to enable the researcher to conduct further data analysis (Mugenda \& Mugenda, 2003).

\subsection{Results}

\subsection{Revenue Performance \& Compliance}

The results show that adherence by counties to the provided guidelines, training, and technical assistance was widely varied and disparate. This ranged from counties that did very little to nothing in enabling and enhancing their OSR, to those that partially and/or conveniently followed guidelines where it suited them, to those that made an honest effort to comply. The observed results are equally varied and mixed but generally counties grossly and consistently underperformed on the OSR measure relative to their own annual projections. Comparing individual county OSR performance for FY 2015/16 with that of $2016 / 17$, only 18 counties registered a positive per capita revenue growth year, while a number of counties had their OSR decline by more than a third.

Figure 2.

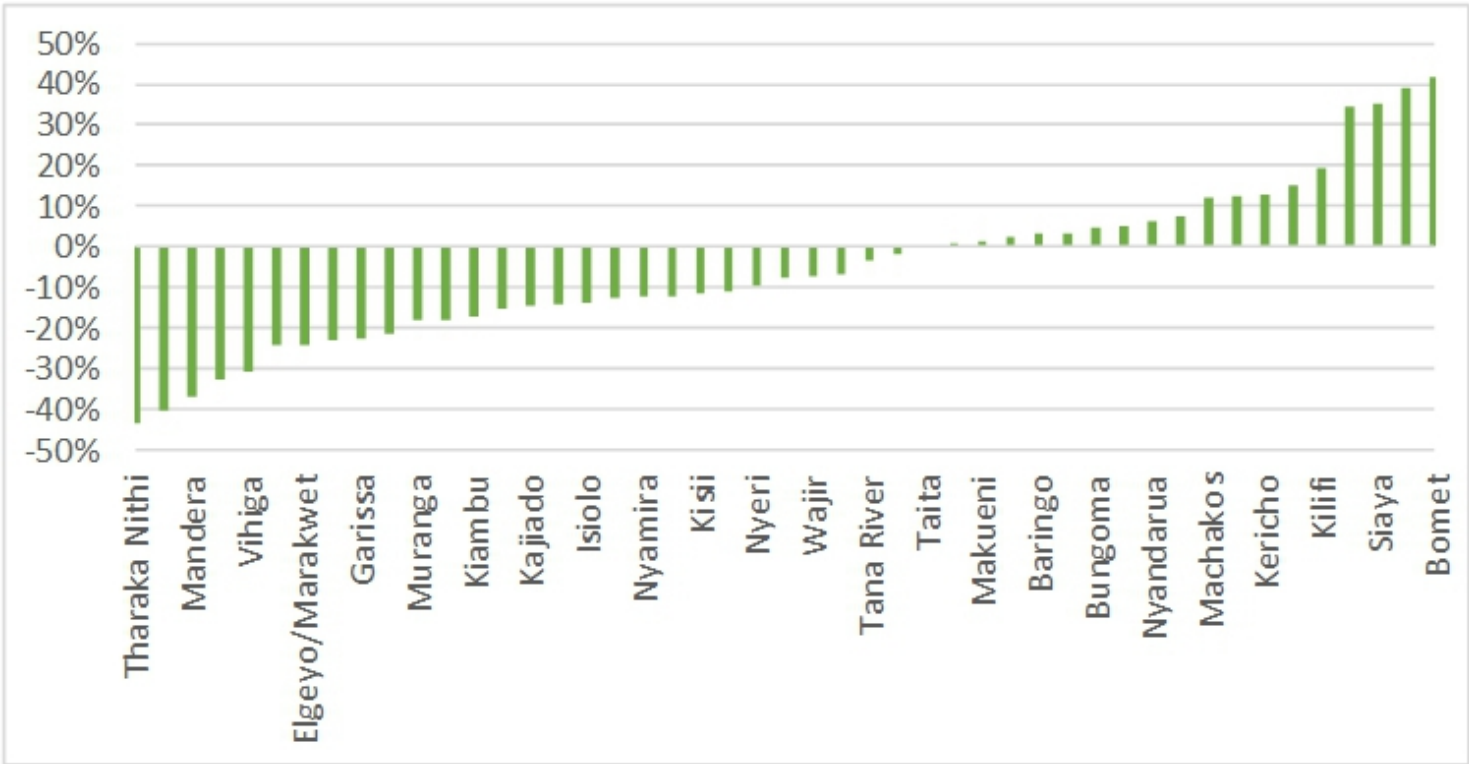

Source: (www.cra.go.ke and Author, 2020)

Decline in a county per capita OSR is a double negative impact in that the affected counties also end up not qualifying for allocations from fiscal effort parameter.

Due to poor OSR performance overall, counties across board are still heavily reliant on equitable share allocations from exchequer relative to OSR, with the latter only comprising an average of $12 \%$ of total revenue. 
Figure 3.

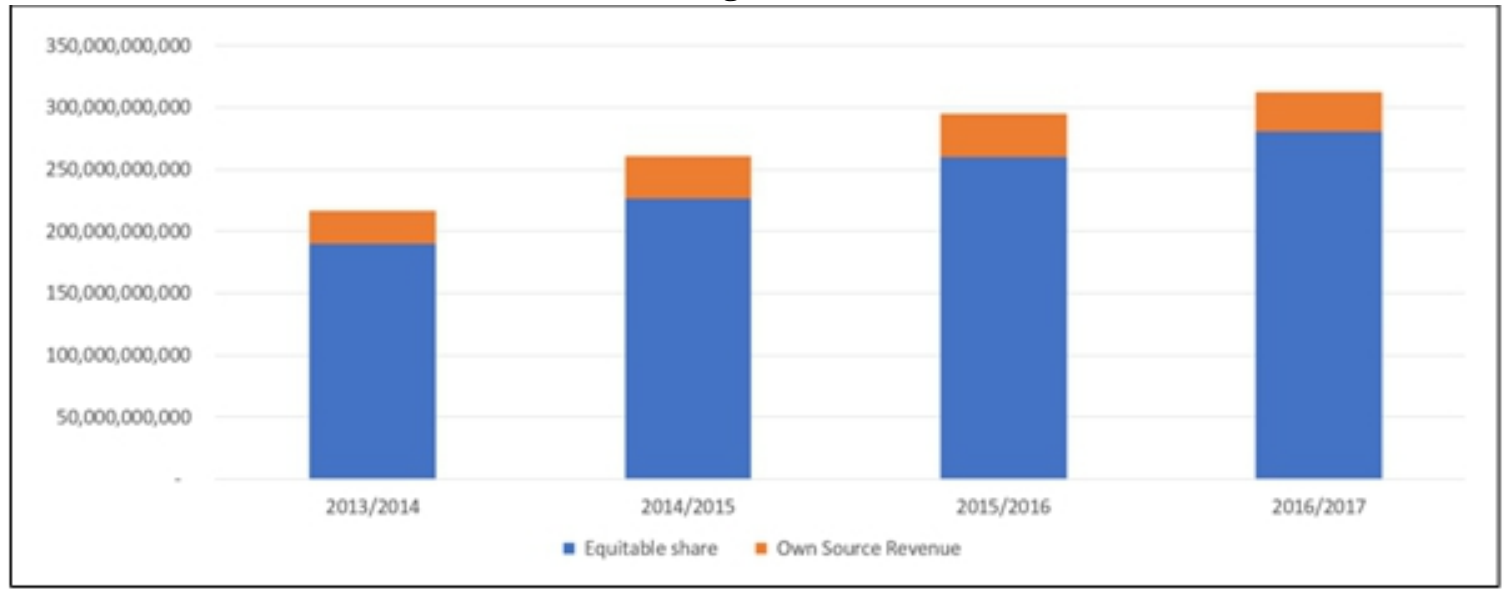

Source: Author, 2020

In the six years between the financial year 2013-2014 and 2018-2019, counties' OSR raised to fund their budget constituted between 9 and 12 percent of the county government budgets.

Figure 4.

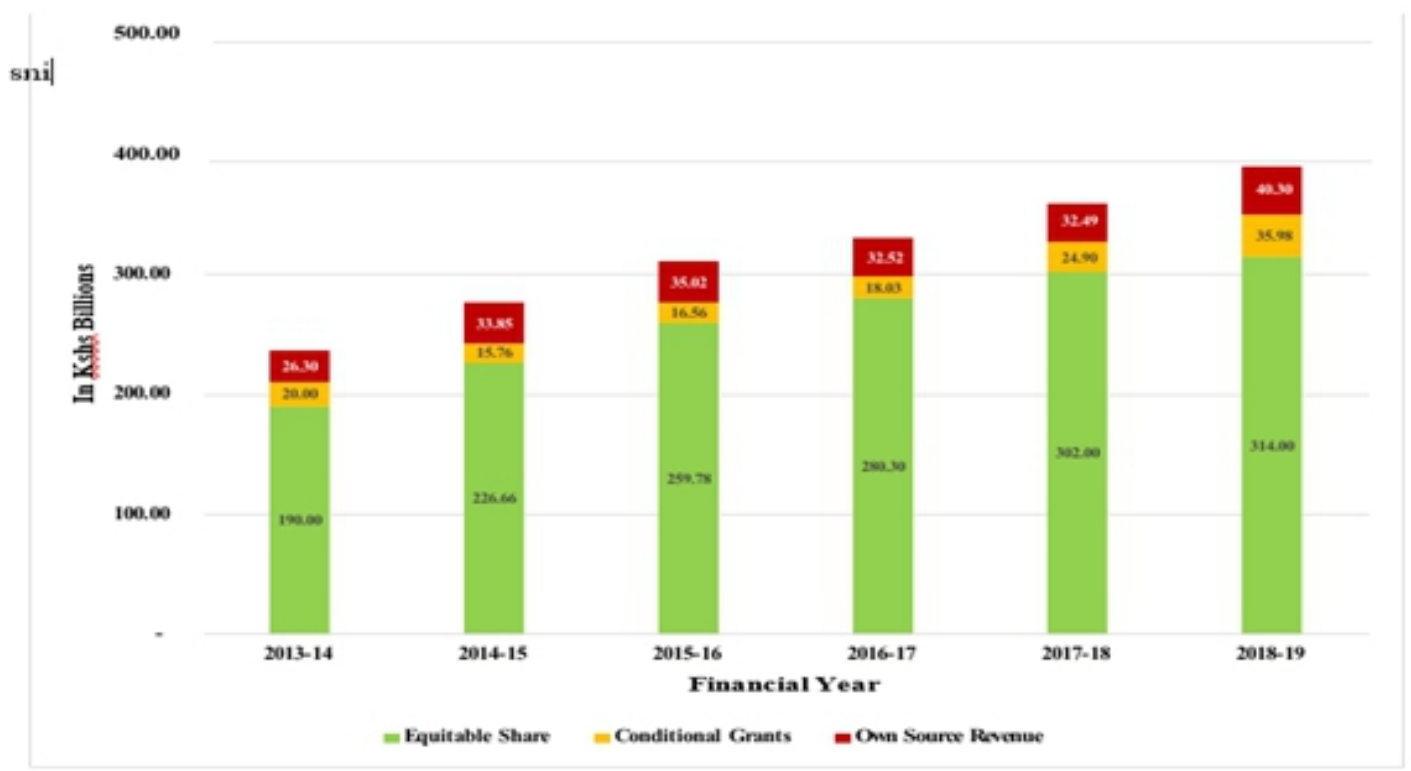

Figure 1: Oww Seurce Revenue Penformance Between FY 2013-14 to FY 2018-19

Source: Author, 2020

The low share of the revenue for county government from OSR is further exacerbated by unrealistic revenue forecasting. Over the past six years, the revenue collected ranged between 49 percent and 75 percent of the targeted collections. 
Figure 5.

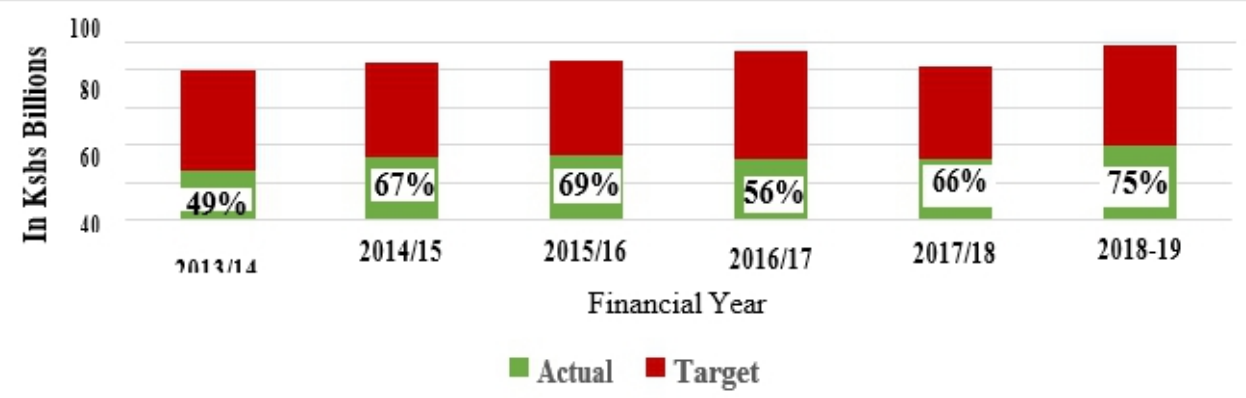

Source: Author, 2020

\subsection{Revenue Automation}

Automation of revenue management mainly involves transition of revenue collection from the use of paper-based receipts to some form of electronic system that facilitates data entry, processing, and reporting of revenue (Mutysia, 2014). The possible solutions vary from USSD wallets to self-service portals. The important aspect of automation is ensuring that convenient and effective service delivery is availed to customers while at the same time provide an effective monitoring and control structure that will avoid revenue leakage (Muthama, 2013).

Automation of revenue collection and management is an important aspect of county government operations. The process is important in ensuring that counties are able to raise enough revenues to support their development agendas. To tap on the full revenue potential of county governments, it is critical to ensure that the process adopts the best technologies. Having an electronic form of revenue collection will be very helpful in sealing revenue leakages. This is because it will provide a way of ensuring customers are correctly charged the appropriate fees whilst also keeping a record of the fees as charged for the purpose of accountability and transparency. It is also clear that the current paper-based process is not adequate to keep records for accounting purposes.

With respect to revenue mobilization and administration, a majority of the counties are facing capacity constraints which range from lack of requisite legislations for enhanced revenue collection to human resource challenges. They still suffer from lack of clarity on the parameters, tools, and benefits at their disposal to maximize own source revenue generation. Furthermore, they have not systemized or rolled out the requisite legal and infrastructural parameters necessary for the purpose of maximizing revenue generation within their borders. Though fervent attempts have been made at redressing some of 
these legislative and institutional challenges, the baseline survey still evidences their continued existence and need for final resolution.

To address some of these challenges and with recent advances in information and communication technology (ICT), there has been a strong drive to use ICT at devolved levels of governance for the purpose of enhancing the efficient collection of tax revenues. It is largely indisputable that when properly configured and deployed, ICT presents many advantages for both taxpayers and governments for it potentially can make paying attractive to taxpayers by making the process of paying taxes/fees simpler, faster, and easier to understand. The above challenges also underscore the need for county governments to enhance revenue generation through a detailed process of identification of revenue streams, the automation of such streams as identified and sealing of all potential room for leakages in collection, and ensuring that the reporting of revenue as collected is accurate.

Against this backdrop and integrated enterprise, wide range revenue collection system that enables county government to perform efficient collection and get up-to-the minute information for prudent decision making is paramount for a county's operation. This is due to the need to optimize on revenue management by installing a fully online integrated electronic payment system which is compatible with all electronic payment and cash transfers in various platforms including mobile, Card, cash, and web-based systems.

The revenue collection system should afford ease of both collections for the county and payments for the citizenry whilst stopping revenue leakages, ensuring adequate information to the public, minimizing operational costs, maximizing revenue collection to support the government's development agenda and services delivery to her citizens. The implementation should be hitched on an electronic collection system that will be used for the collection, validation, update, reporting, management, and reconciliation of all county revenues. The payment channels should include bank, cards, cash, mobile money, ewallets, and USSD. The proposed solution should ensure transparency and accountability of the revenue collection processes, embedded control mechanism, data security, and reliability.

The standard features of an integrated revenue management system include: Taxpayer database linked with the national identifier; Revenue source management; Revenue forecasting; Revenue collection management; Payment processing; Cash and bank reconciliation; Partial payment acceptance; Revenue collectors' management; Payee driven input mechanism; Structured and unstructured streams management; Systems integration capabilities; Easy 
parameter configuration; Reporting capabilities; Systems security; and Systems support \& maintenance.

Therefore, the system should be in line with the legal requirements in Kenya including;

1. The Constitution of Kenya Chapter 12 on public financial management (PFM). Specifically, article 206 states that there shall be established a Revenue Fund for each county government, into which shall be paid all money raised or received by or on behalf of the county government, except money reasonably excluded by an Act of Parliament.

2. Additionally, the PFM Act 2012 lays requirements on the Receiver of revenue to ensure that all revenues as collected are banked intact into the County Revenue Fund.

3. Central Bank of Kenya, CRA and Communication Authority of Kenya requirements.

A proper ICT backed revenue management system is described below;

Figure 6.

County Solutions - High Level Arch.

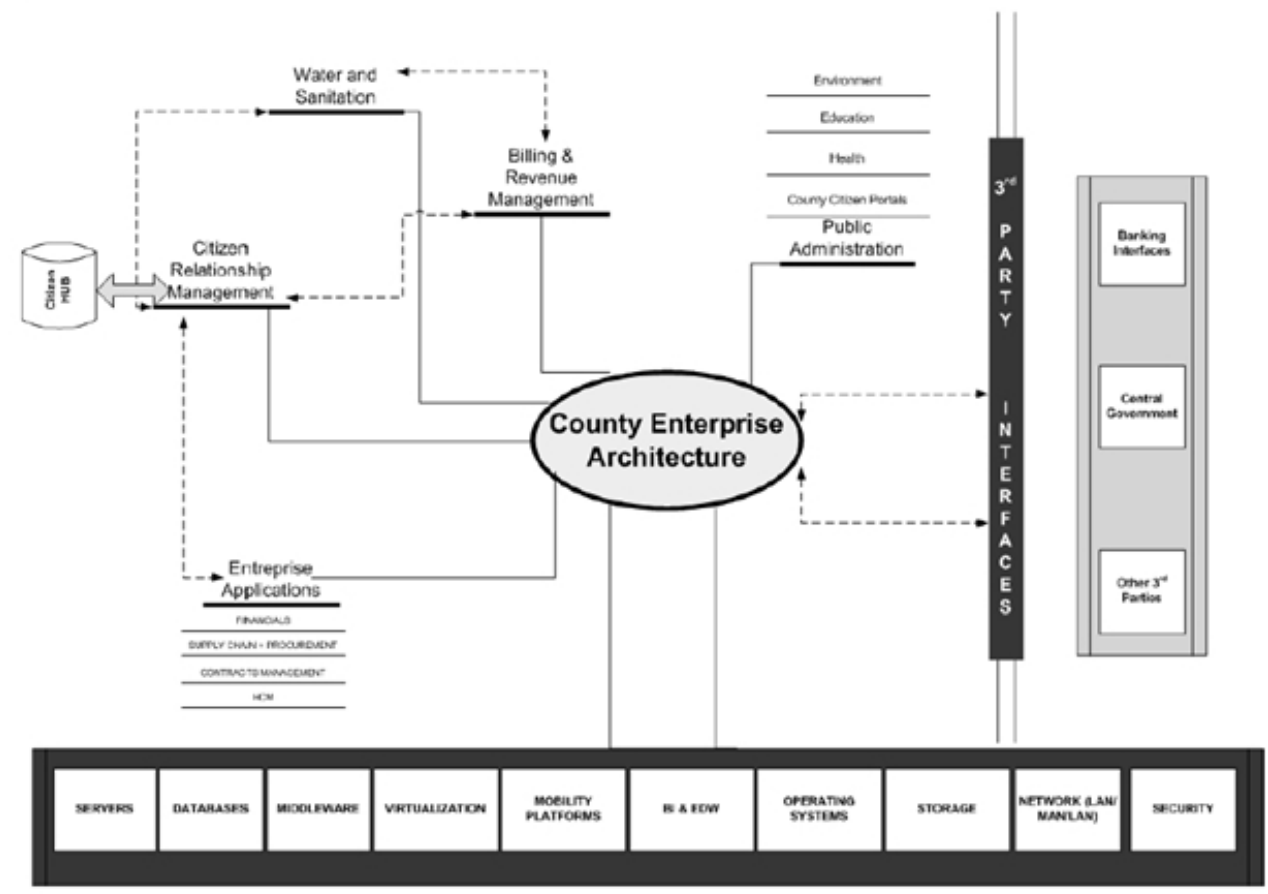

Source: Author, 2020 
Figure 7.

\section{Complete County Solutions!}

\section{Business Intelligence and Decision Support}

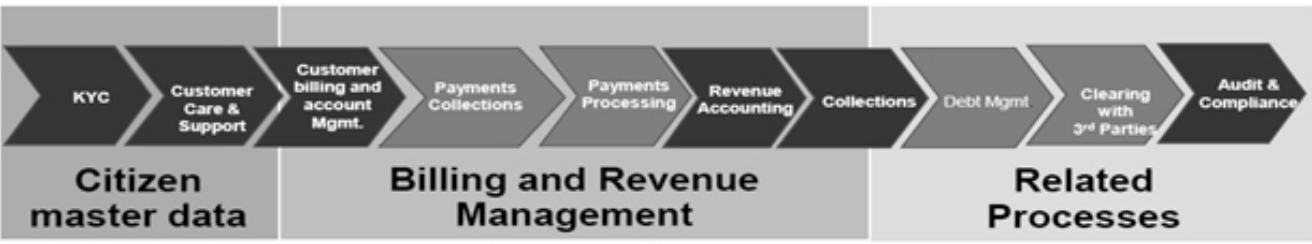

Financials Management

Human Resources Management

Technology (POS, Servers, Network, Card Readers, Integrations)

Source: Author 2020

Figure 8.

\section{Typical Payment Scenario Explained}
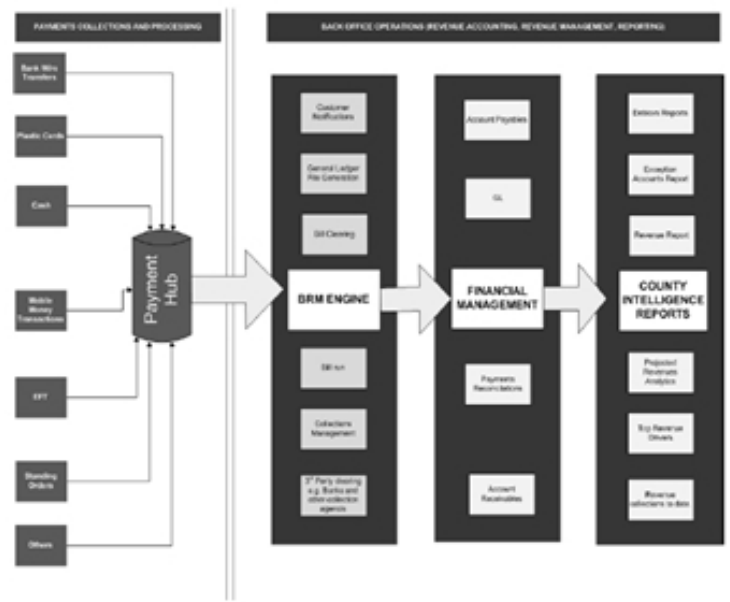

- Prerequisites

- Citizen data mastered centrally in database

- Citizen data model created (Unique Citizen Identifier and Account)

Payment Process

- Customer or County employee initiates a payment request.

- Enters unique customer ID. Account $\#$ and Amount being settled.

- Data entered is validated with back office systems.

- If data is valid, the payment is processed, receipt issued to customer and the accompanying payment information pushed to the BRM engine.

- BRM engine updates the customer accounts information and sends confirmation of payment to customer through SMS.

- BRM Engine publishes payments to the ERP applications for financial accounting procedures.

- Real time updates to embedded reports for insight and decision insights.

Source: Author, 2020 


\section{Figure 9.}

\section{County Operations Snapshot}

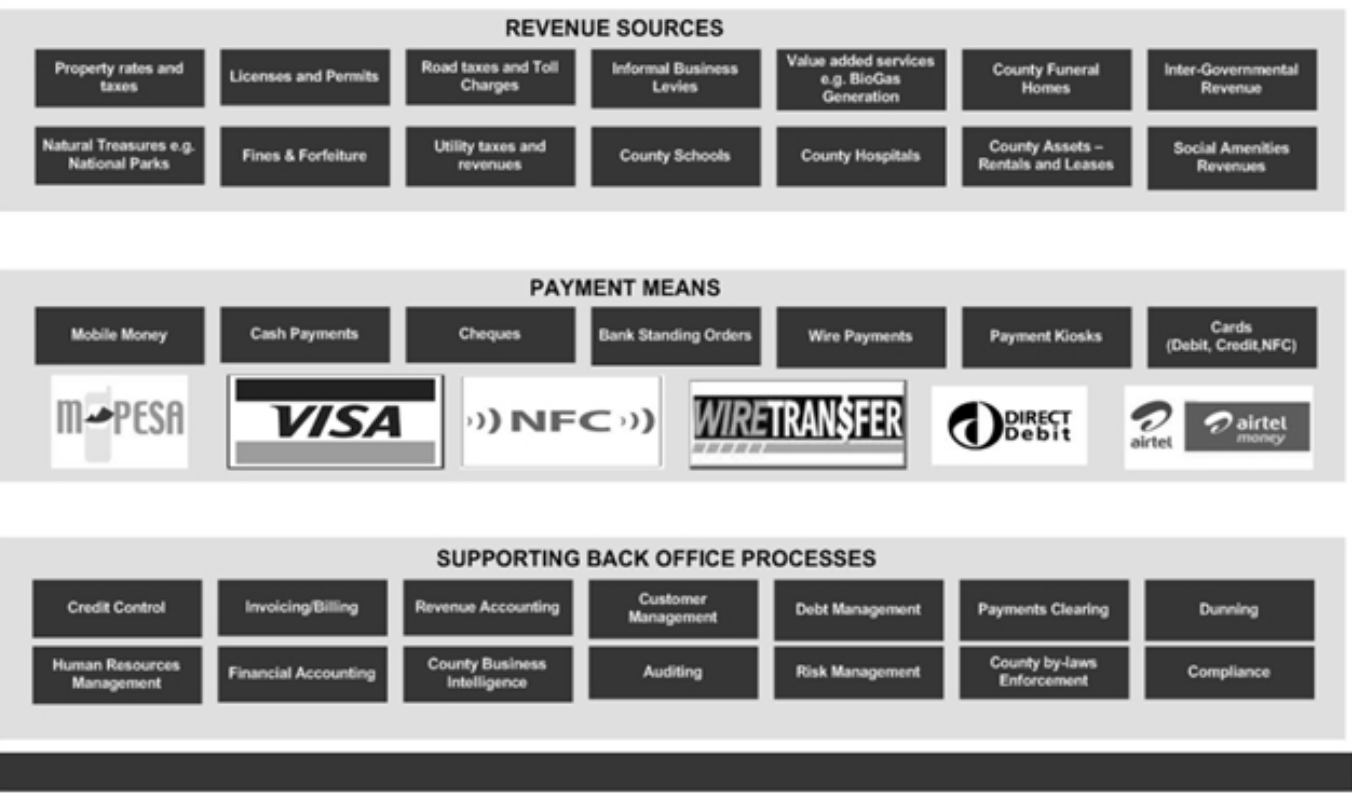

Source: Author, 2020

The system should also have the following key modules and features as depicted in the diagrams below:

Figure 10.
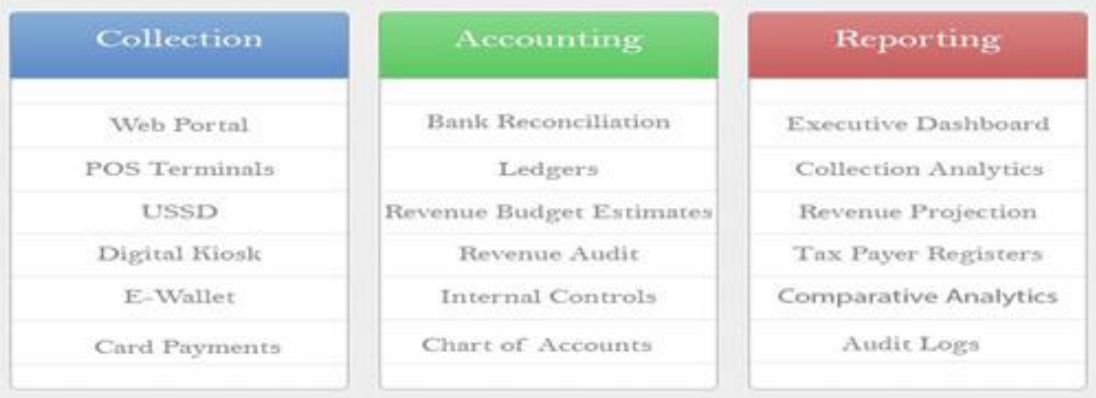

Source: Author, 2020 
Intergrated County Revenue Management Solution Building Blocks Figure 11.

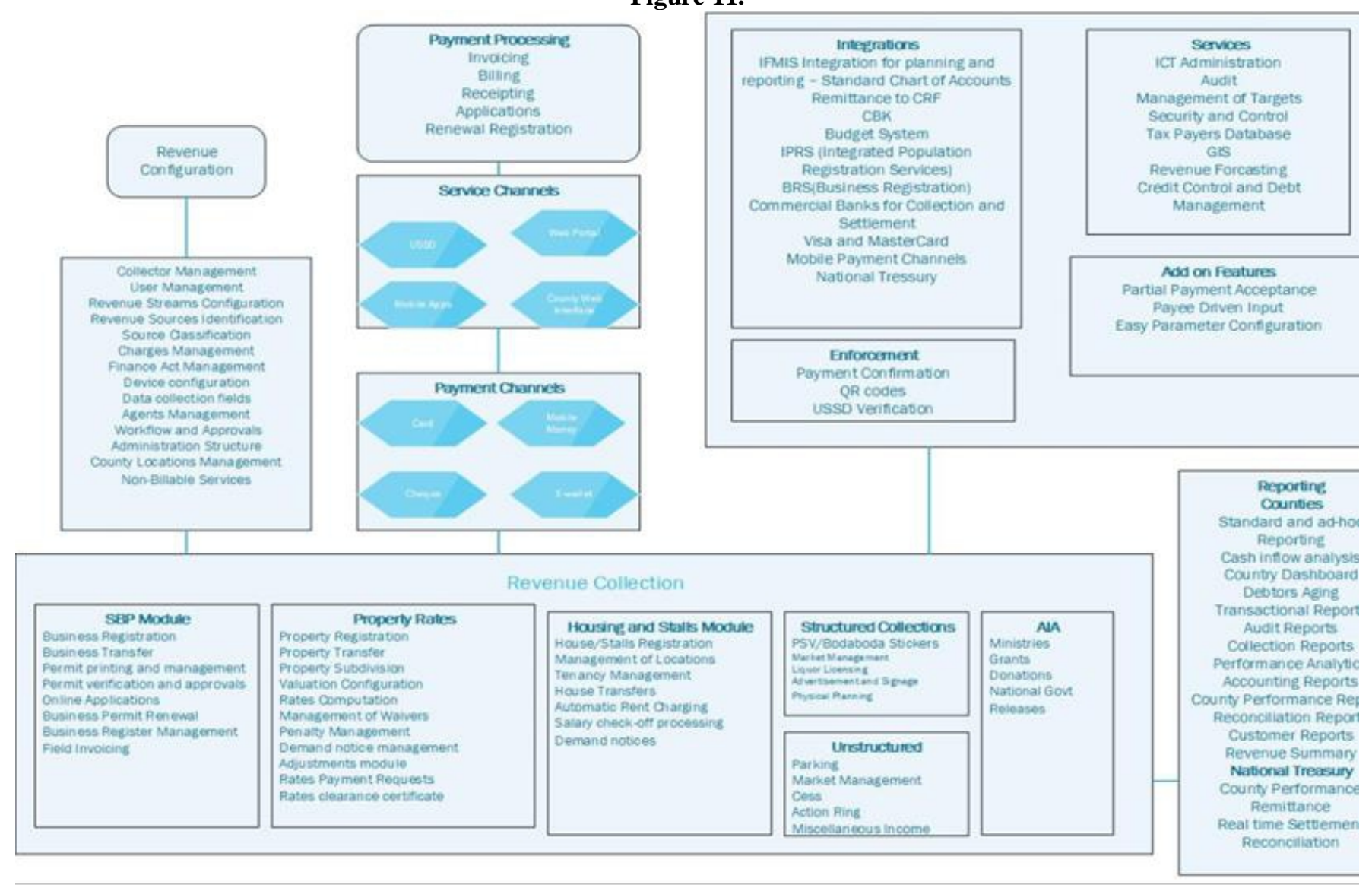

Source: Author, 2020 
Intergrated County Revenue Management Solution Feature List Figure 12.

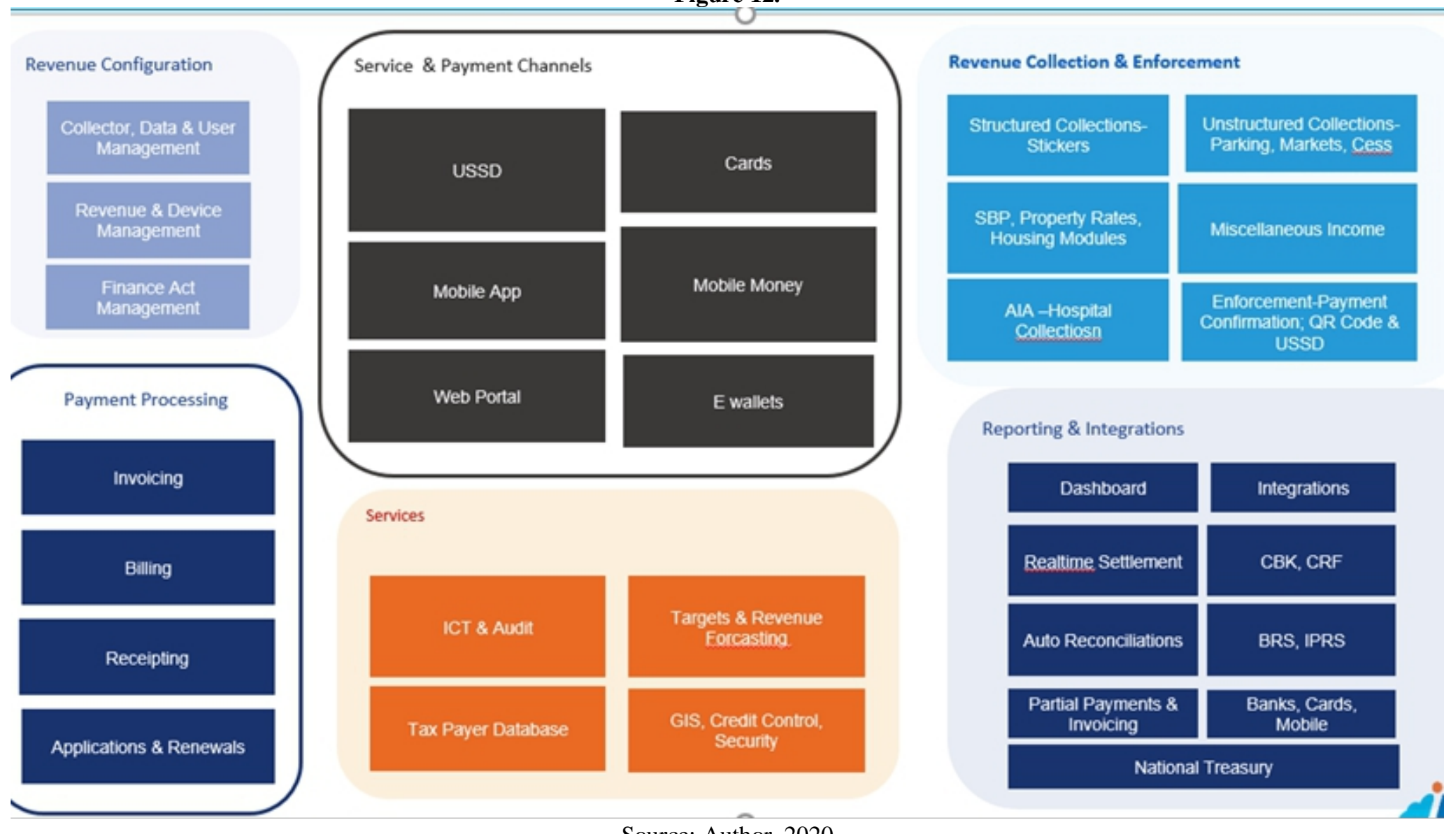

Source: Author, 2020 


\subsection{Challenges in Revenue Automation and Administration}

Optimal Own-Source Revenue (OSR) collection and management is a problem that has consistently bedeviled the county governments ever since the onset of the system of devolved governance in the context of the 2010 Constitution. The manner in which a majority, if not all of the counties, have approached and designed their programs for own-source revenue collection has been and is still fraught with challenges that have largely undermined their efforts to collect optimal revenue. Some of these challenges are historical in nature while the rest are predominantly attributable to capacity constraints, administrative failures, and absence of regulatory and legislative bodies that are critical towards the support of own-source revenue collection.

Basically, this means that since the start of devolution, county officials have given limited attention to policy and legislative frameworks, and they have made little to no investment in staff, administrative processes, and the systems upon which they are predicated. This is as part of the larger need to enhance own-source revenue collection at the county level. It is evident that county officials do not appear to have questioned the public policy purpose of existing fees and charges, their existing legal underpinnings, the link between public policy goals, and the specific revenue sources. Also, the level and price of county charges are not necessarily discussed or reviewed in a systematic manner for the purpose of uniformity, ownership, and most importantly costing, by the respective counties and their departments. Majority of the counties are yet to review the cost implications of the revenue sources that they continue imposing. The critical issue of concern herein is whether or not some of these revenue sources do make economic sense or not. Additionally, it has already been noted that the form and contents of the County Finance Acts have equally not been useful in terms of aiding the counties revenue raising measures as stipulated under the PFM Act, 2012. It was noted that some of the members of the Executive and the County Assemblies do not also appreciate the revenue raising aspects or intentions of these Finance Bills as enacted annually. Thus, the study findings show that most of the counties were mostly facing the challenges as enumerated below;

\section{a) Human Resource Concerns}

In majority of the counties that were surveyed, it was revealed that the revenue officers, under whose docket the task of revenue raising lie, are mostly not permanent staff and thus their levels of attachment to the county governments remain shaky. This in a way impacts on their morale and levels of commitment to the revenue collection process. For instance, in two of the counties, there were reported cases of the staff inherited from the defunct local authority being majorly involved in corrupt practices within the revenue collection processes and a number had so far faced disciplinary proceedings. It was also reported that these cadre of employees mostly resisted the revenue 
automation process. Additionally, the survey brings to the fore the fact that many of the revenue officers overstayed their time in certain locations or even not being transferred at all. This had the effect of making such officers susceptible to corrupt practices, e.g., not charging full fees, colluding with citizens and businesses, inter alia.

\section{b) Service Contracts}

There are quite a number of issues that come to the fore when it comes to the services contracts that the counties have signed with a number of vendors on the provision of revenue automation systems. Of critical importance is the fact that a number of them do not succinctly provide for the terms and conditions that define revenue share between the vendors and the county governments. In addition to this, some of these contracts are not clear on their term durations.

\section{c) Training \& Skills}

The findings show that a number of the revenue collectors are not adequately skilled and thus not entirely effective within the revenue collection chain of events. It was also noted that county revenue officers are not taken through trainings that are specific to their roles but rather through trainings that are very generic. As a result, they are not fully impactful or beneficial to the revenue automation and collection process. This ought to be remedied at the earliest to ensure that the revenue officers only get trained on issues and matters that have a direct and beneficial correlation with the responsibilities that they are assigned within the revenue collection chain.

\section{d) Vendor Support/Onsite Resources}

In most instances, it was noted that the support from the system vendors was not adequate, particularly onsite support services. There were a number of instances where the support services were entirely lacking but even in cases where the support services are existent, they are not adequate or readily available. Some of the problems that were largely experienced included faulty Point of Sale (POS) machines that require repairs or replacement and the vendors inordinately taking time to make good such replacements, and consequently frustrating the process of revenue collection.

\section{e) Partial Automation}

Some of the counties had only partially automated the revenue collection and a number of revenue sources, especially the structured revenue sources which were still manual. 


\section{f) Poor County Services}

Quite a plethora of undesirables affect revenue collection especially at the sub county level. They range from poor roads network, internet connectivity, and basic public services like electricity, water, clean public toilets, poor drainage systems, poor dwellings for revenue staff and lack of security which significantly impacts the process of revenue collection.

\section{g) Poor Revenue Enforcement}

The role of enforcement as a critical component of the revenue collection process cannot be gainsaid. Unfortunately, it was documented that some of the enforcement officers have abandoned their role of enforcement and are now engaged in revenue collection. This assumed role, away from their designated roles, is an opportunity for corrupt individuals to further corrupt practices and thus undermining revenue collection. Essentially, some of these enforcement officers end up collecting revenue that they do not remit to their respective county governments. Additionally, some of the systems do not have good enforcement modules to assist the enforcement officers in their work.

\section{h) Political Interference and Cartels}

There have been instances where movement or activities of revenue staff have been met with stern warnings including drawing the ire of organized cartels that are largely linked to the prevailing political orders within the counties. As a result, such kind of occurrences negatively impact revenue collection due to the collectors being more loyal to their 'masters' than their employers, and in this case the county governments. The cartels go as far as influencing how the revenue collection for unstructured revenues is to be collected especially within the bus parks and markets.

\section{i) Inadequate Revenue Regulatory Framework}

The findings show that most of the counties do not have in place an ideal regulatory framework (legal and policy) for the purpose of reinforcing the revenue collection environment. Some of the counties are yet to pass laws that give them the legislative wherewithal to levy their respective fees, user charges, and taxes. It is also unfortunate that some of the documents that are critical to rating like the valuation roll are yet to be updated. This effectively undermines their ability to raise additional revenue from the payment of rates and related fees. It also emerged that both the revenue collectors and enforcers are ignorant of the county revenue laws for which they purport to enforce. For instance, majority of them are not conversant with their county finance bills or even the rates on which the collections are based. Lastly, it must also be noted that whilst counties have taken the initiative to automate their revenues, they have in some instances ignored the CRA guidelines for one reason or the other. There is no 
standardization in the automation which has left the counties at the mercy of vendors.

\section{j) LAIFOMS' and Parallel Revenue Management Systems}

The use of parallel systems allows for revenue loss or inaccurate capture of data that cannot be verified. The PFM Act 2015 prescribes IFMIS as the system for the handling of public finances within the country. Thus, it is required by law that the automation systems that the counties adopt for revenue collection should be integrated with IFMIS. Unfortunately, the above is not the case. A majority of the counties are still continuously making use of systems like LAIFOMS in violation of the provisions of the Public Finance Management Act. Duplicity of systems is also a sure way of revenue loss for it largely benefits those that are keen on layering the revenue collection process for their own selfish ends.

\section{k) Change Management and Training}

The adoption of technology within the realm of revenue collection has not been enthusiastically received. The findings show that revenue automation is facing resistance in a number of counties for various reasons; some of the revenue collectors are not appreciative or capable of mustering the dexterity that technology demands of them. With such palpable personal inadequacies, they are more keen on resorting to the use of manual systems for after all, that is what they have been accustomed to over the years, and thus plays to their convenience; There is also a cabal of revenue officers who view technology as a form of disruption in the sense that it seals or lessens the room for corrupt practices. Under such circumstances, it is in their best interests that technology does not see the light of day or its implementation is frustrated all together. The foregoing basically explains the resistance that counties are equally facing from their employees who are not comfortable with the accountability and reporting safety guards that technology portends.

\section{l) Network Connectivity}

Connectivity is a challenge in the counties. Without stable and secure connectivity, counties are clearly struggling with automation. This was evident in all the counties. Poor or no network in some cases, even in the sub-county revenue offices, makes it difficult for real-time information flow.

\section{m) Lack of County Data}

Most counties are focusing on the collection of unstructured revenues like markets, parking, and cess. Even though they are not the highest revenue earners, they are rather the easiest ones to collect. Counties are unable to project 
or map revenue collection from the structured sources due to lack of accurate data.

\section{n) Hosting Services}

Without proper infrastructure, counties are not able to host their revenue data and as such most of this information is hosted by the vendor. Such an arrangement is definitely risky. It became apparent during the survey that some of these vendors do not use credible hosting firms. In addition, the counties have procured their own servers and have assigned the vendors to manage the same.

\section{o) Unwillingness of Residents to Pay Rates and Services}

One of the predominant factors that undermine revenue collection is the fact that the residents are unwilling to pay for government services. This reluctance is largely historical as the residents never got acquainted with the delivery of public services as well the concomitant expectation to pay for some of these services which were largely lacking. Therefore, even with the onset of the system of devolved governance, the relationship between cost and service delivery is yet to be properly internalized. Generally, it is felt that if residents frequently paid for services within the required timeframes, that would go a long way in enabling the county government enhance the amount of revenue generated by the county.

\section{p) Service Delivery Satisfaction}

The findings show that citizens were not paying for service delivery simply because they are not able to discern the connection between payment for services and what they actually receive in return. Other residents also feel that the services provided by the county are not entirely satisfactory and thus a reason not to part with any monies towards the payment for services. Value for money is a problem for the county residents from a service delivery perspective and thus leaving the county with a burden of upping its performance from a service delivery standpoint.

\section{Conclusion \& Recommendations}

\section{Recommendations on Revenue Enhancement Strategy}

County governments are suffering from challenges on revenue collection and enhancement. The amount of revenue generated in terms of collection is largely below optimal levels. Hence, there are conscious efforts made by the county to embark on and adopt strategies that enhance its revenue portfolio. Generally, it is argued that increased local revenue promotes local democracy, public accountability, arouses citizen interest in service delivery, and increases the capacity of local leaders to serve their communities in 
accordance with their priorities. In revenue improvement agenda, there are two focus areas: Maximum utilization of current revenue sources through healthy and effective management practices to ensure financial viability or stability and; Creation of new revenue sources/streams for the purpose of enhanced revenue collection on the part of the county government.

Therefore, successful Local Revenue Enhancement (LRE) initiatives must be applied concurrently with processes that can substantially improve efficiency, participation, transparency, accountability, and a direct link between revenues and service provision. The revenue enhancement framework should best be considered through the following three approaches: Revenue administration reforms: revenue policies and laws, assessment, data collection and management, monitoring, reporting and accountability, and enforcement; Expenditure rationalization: efficient expenditure management including separation of service provision from service delivery, waste reduction initiatives, participatory budgeting, accountability, efficient procurement processes, oversight functions, and expenditure tracking systems; and Identification of alternate revenue sources: this applies especially for those sources within the existing legal framework ('low hanging fruits"), and exploring collaborative arrangements based on a sound legal framework.

The first exercise for developing a revenue enhancement plan is analyzing past revenue performance (Trend Analysis). To do so, a list of all revenue items should be produced and their past performance assessed. The trend analysis provides important inputs for further planning. It is also the basis for the subsequent gap analysis. Ideally, performance changes registered within a time span of three years are averaged out. For example, in assessing past performance for rates payments, the following factors ought to be taken into consideration: appropriateness of valuation rolls and rates assessment, timely billing, collection efficiency, and enforcement mechanisms. Based on the foregoing, it is important to analyze the nature and structure of county's revenue items before developing strategies to enhance them. Therefore, all county revenue items should be identified and listed for purposes of allowing for a detailed overview of all revenue sources, and helping to understand the scope of the county's administration mandate and the potential revenue base available.

\section{Conclusion}

Effective tax collection is a very important aspect of county government operations. It is evident that there are so many challenges facing the current paper-based way of tax collection. The main challenge being that most of the money collected is not paid back to the county because loopholes enable revenue collectors to pocket a great share of the amount collected. Revenue management in counties is still fraught with challenges that have 
largely undermined their efforts to collect optimal revenue. Some of these challenges are historical in nature whilst the rest are predominantly attributable to capacity constraints, administrative failures, and absence of regulatory and legislative bodies that are critical to support own-source revenue collection, multiple systems using poorly designed technologies, high cost of automation, systems that are now well supported, and poor change management strategies among others.

The greatest solution to the problem is automation of revenue collection. It cannot be gainsaid that well directed automation of revenue collection and management presents many benefits for county governments, including faster processing of information and data, requiring fewer resources, and reducing the cost of collection. It also increases transparency and is therefore a powerful tool in tackling corruption and reducing the opportunities for bribery. Using ICT to compile a database of information enables revenue authorities to identify and address non-compliant taxpayers. Unfortunately, from the findings of the Baseline Survey Report, these benefits of ICT are yet to be realized in a significant manner due to the various challenges that are manifest in the manner that county governments manage their operations.

In conclusion, it is evident that the county governments have both explored and unexplored potential for revenue. Nonetheless, the most outstanding deficiency and for which the same has to be rectified with utmost urgency revolves around the need for the counties to; Strengthen its policies and regulations by ensuring that they are clear and fully deployed as part of the larger desire for enhanced revenue collection; Ensure that its administrative capacity is enhanced such that the county is able to identity tax (levy) payers, as well ensuring that the collection procedures are clear and transparent; Enhance the local community participation in the process of revenue setting and collection_-The local community would immensely benefit from tax awareness campaigns; and Data collection and use is critical to the revenue collection process. The counties should have data informed strategies that are deployed towards enhanced revenue collection.

\section{References:}

1. Amin, M. A. (2013). Is There an African Resource Curse? Global Human Rights, And International Organizations. Serial No. 113-91

2. Balunywa, W., Nangoli, S., Mugerwa, G. W., Teko, J. \& Mayoka, K. G. (2014). An analysis of fiscal decentralization as a strategy for improving revenue performance in Ugandan Local governments 1. Journal of Research in International Business and Management, 4(2), 2251-28. https://doi.org/10.14303/jribm.2013.011 
3. Davis, F. D. (1989). Perceived Usefulness, Perceived Ease of use and user acceptance of Information Technology, MIS Quart. 1331913339.

4. De Wulf, L. \& Sokol, J. B. (2005).Customs Modernization Handbook (Washington:World Bank).

5. Dramod, K. R. (2004). The Challenges of Tax Collection in Developing Economies, University of Georgia: Georgia.

6. Gidisu, T. E. (2012). Automation System Procedure of the Ghana Revenue Authority on the Effectiveness of Revenue Collection: A Case Study of Customs Division, Unpublished MBA Thesis, Kwame Nkrumah University of Science and Technology.

7. Gutierrez, N. (2006). Issues in Revenue Administration, Tax Compliance, and Combating Corruption. (pp. 49-88), in S. Cnossen \& H-W. Sinn (eds) Public Finance and Public Policy in the New Century (Cambridge, Mass.: MIT Press).

8. Haughton, M. \& Desmeules, R. (2001), Recent Reforms in Customs Administrations, The International Journal of Logistics Management, 12 (1): 65-82.

9. Holniker, D. (2005). Computerization of Commercial Tax System. A Review of Some Efficiency and Macroeconomic Aspects (Chapter 14, pp. 231-263), in V. Tanzi, Policies, Institutions and the Dark Side of Economics (Cheltenham: Edward Elgar).

10. ICPAK (2014), Public Finance Building Blocks for Devolution, Nairobi, Kenya.

11. Kamolo, J. (2014). Machakos Automates Tax Collection, Retrieved from, http://kenyanewsagency.go.ke/?p=3178

12. Kariuki, D. O. (2009). A Study on Systematic Change Management at Kenya Revenue Authority. Unpublished MBA Project, University of Nairobi.

13. Khaunya, F. M., Wawire, P. B. \& Chepng'eno, V. (2015). Devolved Governance in Kenya. Is it a False Start in Democratic, 27-29.

14. Latema, M. O. (2011). Business Models for Revenue Generation and Enhancement Adopted By County Governments in Kenya. University of Nairobi.

15. Mugenda, O. M. \& Mugenda, A. G. (2003). Research methods. Nairobi: ACTS.

16. Muthama, J. (October 2013). Effects of Revenue Systems on KRA. University of Nairobi.

17. Ngotho, J. \& Kerongo, F. (2014). Determinants of Revenue Collection in Developing Countries: Kenya's Tax Collection Perspective. Journal of Management and Business Administration, 1(1). 
18. Prichard, W. (2010). Taxation and State Building: Towards Governance Focused Tax Reform Agenda. IDS Working Paper 341 (May). Brighton: Institute for Development Studies.

19. Ramsey \& Frank (1928). A Mathematical Theory of Saving; economic journal, 38, (December), 543-559.

20. Sanda, A.U., Mikailu A.S. \& Garba, T. (2005). Corporate governance mechanisms and firm financial performance in Nigeria, AERC Research Paper 149, Nairobi.

21. UNCTAD (2008). Use of Customs Automation Systems, Trust Fund for Trade Facilitation Negotiations, Technical Note No. 3, New York.

22. Visser, C. B., Christiaan, B. \& Erasmus, P. W. (2005). The management of public finance : a practical guide. Oxford University Press. 